\title{
Optimal Timing of Surgical Excision in Pediatric Pilomatricoma: Association between Clinicopathological Features and Cosmetic Outcomes
}

\author{
Yong Woo Oh*, Ho Seok Suh, Yu Sung Choi* \\ Department of Dermatology, Ulsan University Hospital, University of Ulsan College of Medicine, Ulsan, Korea
}

Background: The treatment of choice for pilomatricomas is surgical excision; however, data for the optimal timing of treatment and cosmetic outcomes are limited. Objective: This study aimed to investigate the optimal timing of treatment in pilomatricomas by considering clinicopathological findings and cosmetic outcomes. Methods: Seventy-three pilomatricomas patients aged $\leq 15$ years were retrospectively reviewed. Patients were classified into early excision (disease duration $\leq 12$ months, group A) and delayed excision groups (disease duration $>12$ months, group B). Tumor characteristics, and histopathological features with evolutionary stages were assessed. Cosmetic outcomes were evaluated by the Modified Vancouver Scar Scale (MVSS), 5-point patient satisfaction score, and complication rates. Results: Group A showed better cosmetic outcomes than group B in the MVSS $(1.53 \pm 1.22$ vs. $3.68 \pm 1.84)$, 5-point patient satisfaction score $(4.08 \pm 0.89$ vs. $3.18 \pm 1.01)$, and complication rates $(11.8 \%$ vs. $36.4 \%)$, respectively $(p<0.05)$. Secondary anetoderma, tent sign, calcification, and late regressive stage (evolutionary stage IV) were more common in group $B$, $(p<0.05)$. Moreover, evolutionary stages showed a positive

Received September 16, 2019, Revised October 28, 2019, Accepted for publication November 12, 2019

*These authors have equally contributed to the article.

Corresponding author: Yu Sung Choi, Department of Dermatology, Ulsan University Hospital, University of Ulsan College of Medicine, 877 Bangeojinsunhwando-ro, Dong-gu, Ulsan 44033, Korea. Tel: 82-52-250-7090, Fax: 82-52-250-7155, E-mail: uuhderma@daum.net

ORCID: https://orcid.org/0000-0001-8308-4091

This is an Open Access article distributed under the terms of the Creative Commons Attribution Non-Commercial License (http://creativecommons. org/licenses/by-nc/4.0) which permits unrestricted non-commercial use, distribution, and reproduction in any medium, provided the original work is properly cited.

Copyright $($ c The Korean Dermatological Association and The Korean Society for Investigative Dermatology correlation with mean MVSS ( $r=0.670, p<0.05)$. Conclusion: Early excision (disease duration $\leq 12$ months) provides superior cosmetic outcomes compared to delayed procedures. Early recognition, diagnosis, and management for pediatric pilomatricomas is important to improve overall cosmetic outcomes. (Ann Dermatol 32(2) $93 \sim$ 100, 2020)

\section{-Keywords-}

Cosmetic outcomes, Evolutionary stages, Pilomatricoma, Surgical excision, Surgical outcomes

\section{INTRODUCTION}

Pilomatricomas is a benign skin tumor that originates from the hair follicle matrix. Although it can develop in patients of any age, it usually affects children and adolescents. Clinically, it presents as a solitary, firm, subcutaneous nodule with normal surface skin color. It can occur at any hairbearing region, but has a predilection for the head and neck, which is conspicuous and cosmetically sensitive areas $^{1-4}$. On biopsy examination, it shows a progressing spectrum of histopathological features that reflect different evolutionary stages $^{4-6}$.

Surgical excision is a treatment of choice; however, pilomatricomas is occasionally neglected because most tumors are asymptomatic, slow growing, and small in size ${ }^{7}$. Moreover, elective pediatric dermatologic procedures are often delayed as patients are too young to cooperate under local anesthesia, and parents are unfriendly to general anesthesia. However, if tumors are left untreated for an extended time, histopathological progression results in tissue damage due to inflammation and calcification, which can affect cosmetic outcomes ${ }^{4,8-12}$. Therefore, it is important to de- 
termine the optimal timing for treatment in pilomatricomas. Data on the postoperative outcomes of pilomatricomas, which influence on the appropriate timing for tretment, are limited. Thus, this study aimed to determine the optimal timing for treatment, to evaluate overall cosmetic outcomes, and to identify whether they were associated with clinicopathological findings of pilomatricomas through a clinical study of 73 pediatric patients.

\section{MATERIALS AND METHODS}

\section{Study design and population}

A retrospective chart review was conducted for patients who aged $\leq 15$ years, histopathologically diagnosed with pilomatricomas, and treated by surgical excision and primary closure at the UIsan University Hospital (UUH) from January 2010 to June 2018. During the period, a total of 95 patients were screened, and we excluded patients with immunosuppression $(n=2)$, two or more tumors $(n=2)$, circular/punch excision $(n=9)$, slit excision with dissection $(n=3)$, and follow-up loss $(n=6)$. Finally, a total of 73 patients with elliptical excision and primary linear closure were eligible for the study (Fig. 1).

Disease duration was defined as the time from the patient's recognition of the tumor to the date of surgery. Based on previous studies ${ }^{1,7}$, the disease duration of 12 months was used as a cutoff period for classifying the early excision group (disease duration $\leq 12$ months, group A) and delayed excision group (disease duration $>12$ months, group B). Clinical photographs of the tumor were taken using standardized photography (P500; Nikon, Tokyo, Japan) before surgery and at follow-up visits. The follow-up time points were postoperative days (POD) 2, 7, and 14 , and 6 months after surgery.
The Institutional Review Board of the UUH approved this study (IRB no. UUH-2018-07-015). The study was conducted in accordance with the Declaration of Helsinki, and informed consent about publishing all photographic materials was obtained from all participants.

\section{Demographics and tumor characteristics}

Baseline demographics and tumor characteristics were documented for all patients. Anatomical locations were divided into head and neck, trunk, and extremities. The tumor size was measured in square centimeters. The tent sign referred to the presence of multiple facets and angles when the overlying skin is stretched.

\section{Histopathology and evolutionary stages}

All specimens were stained with hematoxylin and eosin for histopathological examination and reviewed by two dermatologists (HS Suh and YS Choi). Histopathological features including inflammation, multinucleated giant cells, hemorrhage, and calcification were assessed. Based on a previous studies of evolutionary stages in pilomatricoma, tumors were classified into four distinct stages: early (stage I), fully developed (stage II), early regressive (stage III), and late regressive (stage IV) ${ }^{4-6,13}$.

\section{Surgical outcomes}

Surgical outcomes were evaluated by two dermatologists (YW Oh and HS Suh) at POD 2, and 7, and 6 months after surgery. Early complications including pain, hemorrhage, hematoma, seroma, dehiscence, and secondary infection were evaluated at POD 2 and 7. Cosmetic complications including erythema, post-inflammatory hyperpigmentation $(\mathrm{PIH})$, hypertrophy, atrophy, and wound widening were evaluated at postoperative 6 months. The Modified Vanc-

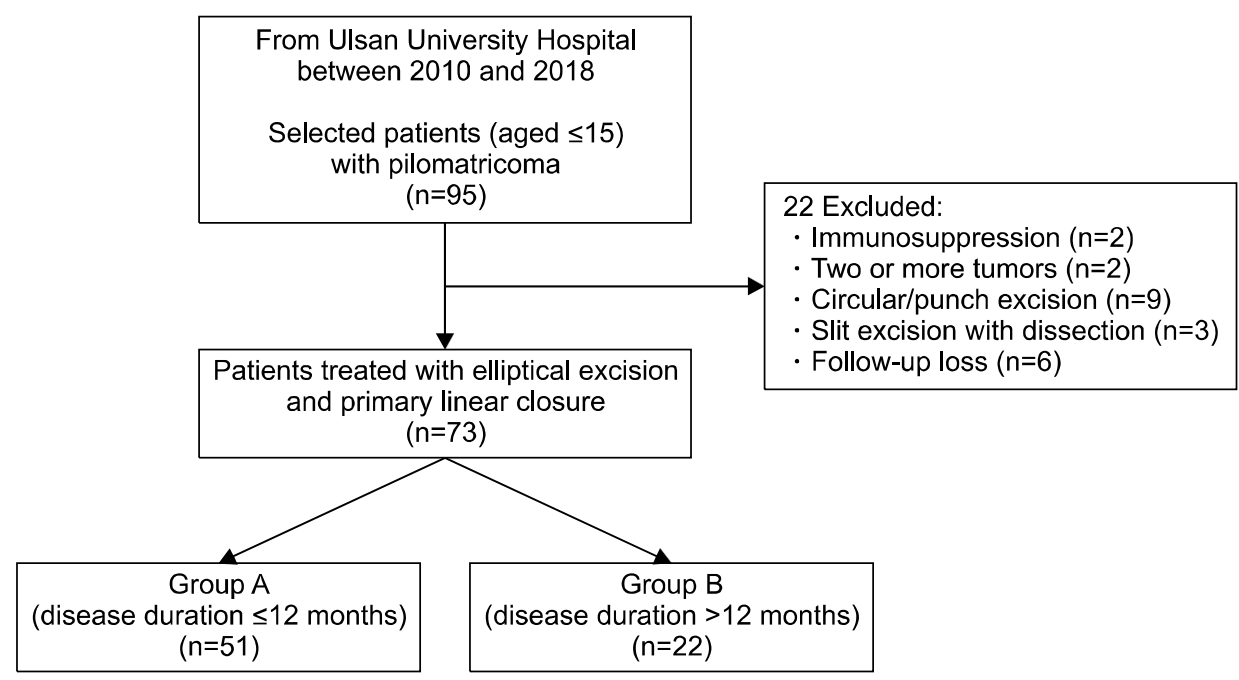

Fig. 1. Flow and distribution of patients according to disease duration. Group A: early excision group, group B: delayed excision group. 
ouver Scar Scale (MVSS) ${ }^{14,15}$ and 5-point patient satisfaction score (graded from 1 [very poor] to 5 [excellent]) were evaluated at postoperative 6 months.

\section{Surgical procedures}

All procedures were performed by the same dermatologic surgeon (YS Choi) with the following protocol: 1) after skin preparation, local anesthesia with $1 \%$ lidocaine and 1:100,000 epinephrine was administered. 2) An elliptical excision with primary linear closure was designed considering the tumor axis and the skin tension line. The major axis was designed as short as possible for better cosmetic results. 3) A skin incision was made, and the entire tumor was excised along with a margin of normal tissue on all sides. 4) An intradermal absorbable vicryl suture was placed followed by superficial nylon sutures. 5) The surgical site was covered with sterile gauze and elastic bandages for 2 days, which exerted pressure for the purpose of achieving fixation, hemostasis, and protection. 6) Dress- ings were changed with hydrocolloid dressing material (Duoderm Extra Thin; ConvaTec Inc., Greensboro, NC, USA) on POD2 and 7. 7) Finally, sutures were removed after $10 \sim 14$ days.

\section{Statistical analysis}

Categorical variables were described as numbers with percentages, and continuous variables were described as mean with standard deviation. Pearson's chi-square test and Fisher's exact test were used to compare categorical variables between groups. Comparisons of continuous variables were performed using the Mann-Whitney U-test. Pearson correlation analysis was used to verify the correlations between the evolutionary stages and the mean MVSS. A $p<0.05$ indicated statistical significance. All statistical analyses were conducted using IBM SPSS Statistics, ver. 21 (IBM Corp., Armonk, NY, USA).

Table 1. Comparison of baseline demographics and tumor characteristics between the early excision group and delayed excision group

\begin{tabular}{|c|c|c|c|c|}
\hline Characteristic & $\begin{array}{l}\text { Total } \\
(\mathrm{n}=73)\end{array}$ & $\begin{array}{c}\text { Group A } \\
(n=51)\end{array}$ & $\begin{array}{c}\text { Group B } \\
(\mathrm{n}=22)\end{array}$ & $p$-value* \\
\hline \multicolumn{5}{|l|}{ Demographics } \\
\hline Sex & & & & 0.486 \\
\hline Male & $32(43.8)$ & $21(41.2)$ & $11(50.0)$ & \\
\hline Female & $41(56.2)$ & $30(58.8)$ & $11(50.0)$ & \\
\hline Age of onset $(y r)^{*}$ & $6.75 \pm 3.51$ & $6.73 \pm 3.61$ & $6.81 \pm 3.35$ & 0.445 \\
\hline Disease duration (mo) & $9.48 \pm 10.59$ & $4.92 \pm 2.49$ & $20.05 \pm 14.23$ & 0.000 \\
\hline \multicolumn{5}{|l|}{ Tumor characteristics } \\
\hline Size $\left(\mathrm{cm}^{2}\right)$ & $1.86 \pm 0.73$ & $1.85 \pm 0.79$ & $1.86 \pm 0.58$ & 0.403 \\
\hline Anatomic location & & & & 0.160 \\
\hline Head and neck & $46(63.0)$ & $34(66.7)$ & $12(54.5)$ & \\
\hline Cheek & $17(37.0)$ & $14(41.2)$ & $3(25.0)$ & \\
\hline Periorbital region & $7(15.2)$ & $5(14.7)$ & $2(16.7)$ & \\
\hline Temporal region & $7(15.2)$ & $6(17.6)$ & $1(8.3)$ & \\
\hline Neck & $6(13.0)$ & $4(11.8)$ & $2(16.7)$ & \\
\hline Forehead & $4(8.7)$ & $1(2.9)$ & $3(25.0)$ & \\
\hline Scalp & $3(6.5)$ & $2(5.9)$ & $1(8.3)$ & \\
\hline Mandibular region & $2(4.3)$ & $2(5.9)$ & $0(0.0)$ & \\
\hline Extremity & $21(28.8)$ & $15(29.4)$ & $6(27.3)$ & \\
\hline Trunk & $6(8.2)$ & $2(3.9)$ & $4(18.2)$ & \\
\hline Surface color change & & & & 0.257 \\
\hline Without & $56(76.7)$ & $41 \quad(80.4)$ & $15(68.2)$ & \\
\hline With & $17(23.3)$ & $10(19.6)$ & 7 (31.8) & \\
\hline Secondary anetoderma & & & & 0.002 \\
\hline Without & $59(80.8)$ & $46(90.2)$ & $13(59.1)$ & \\
\hline With & $14(19.2)$ & $5(9.8)$ & $9(40.9)$ & \\
\hline Tent sign & & & & 0.000 \\
\hline Without & $44(60.3)$ & $38(74.5)$ & $6(27.3)$ & \\
\hline With & $29(39.7)$ & $13(25.5)$ & $16(72.7)$ & \\
\hline
\end{tabular}

Values are presented as number (\%) or mean \pm standard deviation. Group A: early excision group, group B: delayed excision group. *Analyzed by Mann-Whitney test, chi-square test, Fisher's exact test or independent t-test. 
Table 2. Comparison of evolutionary stages and histopathological features between groups

\begin{tabular}{lcccc}
\multicolumn{1}{c}{ Characteristic } & $\begin{array}{c}\text { Total } \\
(\mathrm{n}=73)\end{array}$ & $\begin{array}{c}\text { Group A } \\
(\mathrm{n}=51)\end{array}$ & $\begin{array}{c}\text { Group B } \\
(\mathrm{n}=22)\end{array}$ & $p$-value* \\
\hline $\begin{array}{l}\text { Histopathological features } \\
\quad \text { Calcification }\end{array}$ & $47(64.4)$ & $26(51.0)$ & $21(95.5)$ & 0.000 \\
$\quad$ Inflammation & $41(56.2)$ & $31(60.8)$ & $10(45.5)$ & 0.226 \\
$\quad$ Multinuclear giant cells & $37(50.7)$ & $24(47.1)$ & $13(59.1)$ & 0.345 \\
$\quad$ Hemorrhage & $14(19.2)$ & $10(19.6)$ & $4(18.2)$ & 0.887 \\
Evolutionary stages & & & & 0.000 \\
$\quad$ Stage I & $4(5.5)$ & $4(7.8)$ & $0(0.0)$ & $5(0.0)$ \\
$\quad$ Stage II & $19(26.0)$ & $19(37.3)$ & $5(22.7)$ & $17(77.3)$ \\
$\quad$ Stage III & $31(42.5)$ & $26(51.0)$ & $2(3.9)$ & \\
Stage IV & $19(26.0)$ & & \\
\hline
\end{tabular}

Values are presented as number (\%). Group A: early excision group, group B: delayed excision group. *Analyzed by Mann-Whitney test, chi-square test, Fisher's exact test or independent t-test. ${ }^{\dagger}$ Evolutionary stages according to Kaddu et al. ${ }^{5}$.

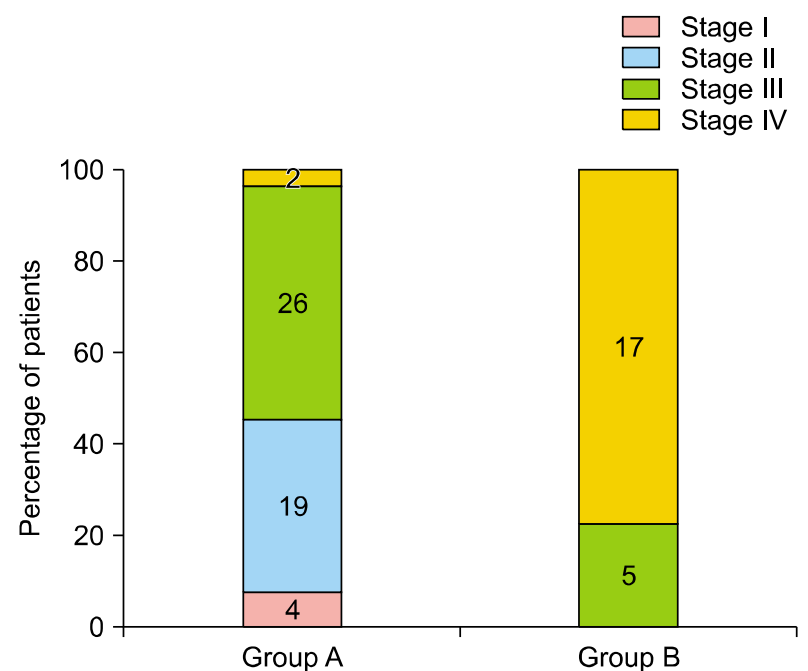

Fig. 2. Percentage of patients according to the evolutionary stages in both groups. The number of patients within each evolutionary stage is shown. Group A: early excision group, group B: delayed excision group.

\section{RESULTS}

\section{Demographics and tumor characteristics}

This study enrolled 73 pediatric pilomatricomas patients, of which 51 patients $(69.9 \%, 51 / 73)$ were in group A (disease duration $\leq 12$ months) and 22 patients (30.1\%, 22/73) were in group B (disease duration $>12$ months). The mean age of onset was $6.75 \pm 3.51$ years. The mean disease duration was $9.48 \pm 10.59$ months $(4.92 \pm 2.49$ months in group $A, 20.05 \pm 14.23$ months in group $B)(p<$ 0.05).

Most patients had tumor on their head and neck area $(63.0 \%, 46 / 73)$, followed by extremities $(28.8 \%, 21 / 73)$, and trunk $(8.2 \%, 6 / 73)$. The cheek is the most common

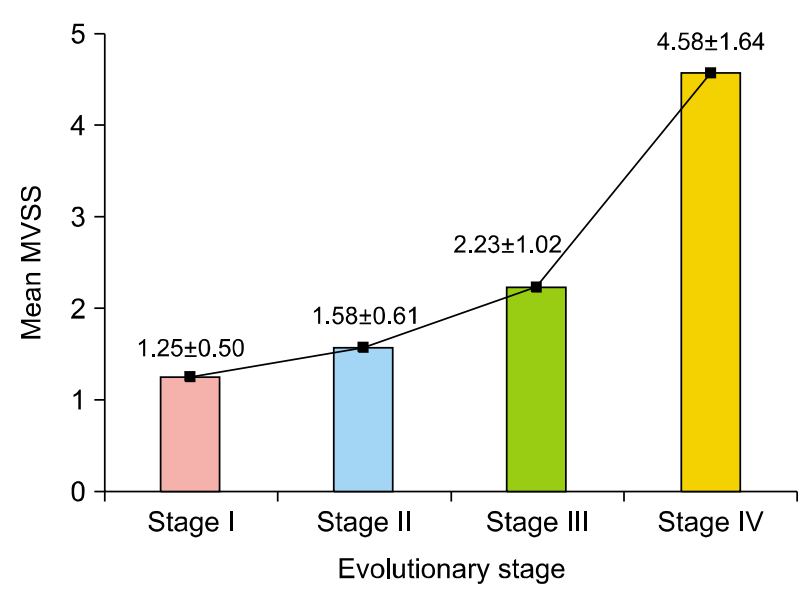

Fig. 3. Positive correlation between the mean Modified Vancouver Scar Scale (MVSS) score and the evolutionary stages in all patients $(r=0.670, p<0.05)$. The mean modified vancouver scar scale score in each evolutionary stage is shown.

site of head and neck area in both groups (41.2\%, 14/34 in group $A$, and $25.0 \%, 3 / 12$ in group $B)$. The mean tumor size was $1.86 \pm 0.73 \mathrm{~cm}^{2}\left(1.85 \pm 0.79 \mathrm{~cm}^{2}\right.$ in group $A$, and $1.86 \pm 0.58 \mathrm{~cm}^{2}$ in group B) $(p>0.05)$. Fifty-six patients $(76.7 \%, 56 / 73)$ exhibited normal overlying skin color $(80.4 \%, 41 / 51$ in group $A$, and $68.2 \%, 15 / 22$ in group B) $(p>0.05)$. Fourteen patients $(19.2 \%, 14 / 73)$ showed secondary anetoderma, which was more common in group B $(40.9 \%, 9 / 22)$ than in group A $(9.8 \%, 5 / 51)(p<0.05)$. There was no evidence of perforation or transepidermal elimination in any patient (data not shown). The tent sign was more common in group $B(72.7 \%, 16 / 22)$ than in group A $(25.5 \%, 13 / 51)(p<0.05)$. Both secondary anetoderma and tent sign were more common in group $B$ than in group $\mathrm{A}(p<0.05)$. However, no significant difference was observed for location, size, or overlying skin color change between groups ( $p>0.05$ ) (Table 1$)$. 


\section{Histopathological features and evolutionary stages}

Various degrees of inflammatory cell infiltrate predominated by lymphohistiocytes and multinucleated giant cells were observed in both groups. Calcification was more common in group B $(95.5 \%, 21 / 22)$ than in group A $(51.0 \%$, $26 / 51) \quad(p<0.05)$. However, no significant differences were found in inflammatory cell infiltrates, multinucleated giant cells, and hemorrhage between groups $(p>0.05)$. The most common evolutionary stage was stage III in group A $(51.0 \%, 26 / 51)$ and stage IV in group B $(77.3 \%$, $17 / 22)$. Stages I, II, and III were more common in group A than in group $B(p<0.05)$, and inversely, stage IV was more common in group $B$ than in group $A(p<0.05)$ (Table 2, Fig. 2).

\section{Surgical outcomes}

No early complications occurred at POD 2 or POD 7 in either group. Fourteen $(19.2 \%, 14 / 73)$ patients showed at least one cosmetic complications at postoperative 6 months. These patients had multiple complications. The overall cosmetic complication rates were higher in group $B$ $(36.4 \%, 8 / 22)$ than in group A $(11.8 \%, 6 / 51)(p<0.05)$. Erythema, $\mathrm{PIH}$, and atrophy were more common in group $B$ than in group A $(p<0.05)$. However, no significant differences in wound widening or hypertrophy were noted between groups $(p>0.05)$.

The mean MVSS was $2.18 \pm 1.73$, which was lower in group $A(1.53 \pm 1.22)$ than in group $B(3.68 \pm 1.84)(p<$ $0.05)$. In addition, there was a positive correlation between evolutionary stages and the mean MVSS $(r=0.670$, $p<0.05$ ) (Fig. 3). Most patients were satisfied with their surgical outcomes at postoperative 6 months. The mean 5 -point patient satisfaction score was $3.81 \pm 1.01$, which was higher in group $A(4.08 \pm 0.89)$ than in group $B$ $(3.18 \pm 1.01 ; p<0.05)$ (Table 3, Fig. 4, 5).

\section{DISCUSSION}

Because most pilomatricomas appear as asymptomatic, slow-growing, and skin-colored nodules, and tent signs are often negative, preoperative diagnostic accuracy is low. The diagnostic accuracy of pilomatricomas was $16 \% \sim 54.4 \%{ }^{16-18}$. Low diagnostic accuracy subsequently results in delayed intervention and poor cosmetic outcomes; thus, meticulous observation of skin lesions is necessary for both patients and physicians.

Surgical excision is the treatment of choice for most benign skin tumors including pilomatricomas. However, in contrast to other benign tumors, pilomatricomas shows inflammation, calcification, and ossification in histopathology, which can cause additional tissue damage ${ }^{4-6,19}$. In turn, subclinical tissue damage can affect the wound healing process and cosmetic outcomes ${ }^{8,10,11}$. In this study, the delayed excision group showed worse cosmetic outcomes compared to the early excision group in the MVSS, 5 -point patient satisfaction score, and complication rates $(p<0.05)$.

Secondary anetoderma was more common in group $\mathrm{B}$ $(40.9 \%)$ than in group A $(9.8 \%)$. The pathogenesis of anetoderma overlying pilomatricoma is unclear; however, histopathologically, dermal elastic fiber degeneration, atrophy, edema, and inflammatory cell infiltrates are observed $^{4,10,12}$. Our findings suggest that elastolysis and catalytic mechanisms are more progressive in patients with delayed excision. As secondary anetoderma with underlying histopathological change can affect delayed wound healing and scar formation ${ }^{10,20,21}$, it would be associated with poor surgical outcomes.

The tent sign on physical examination is a pathognomonic sign of pilomatricomas. It is related to already developed calcification and ossification, which make tumor hard and uneven $^{3,22,23}$. In this study, $39.7 \%$ of the patients showed a

Table 3. Comparison of surgical outcomes between groups

\begin{tabular}{lcccc}
\hline \multicolumn{1}{c}{ Characteristic } & $\begin{array}{c}\text { Total } \\
(\mathrm{n}=73)\end{array}$ & $\begin{array}{c}\text { Group A } \\
(\mathrm{n}=51)\end{array}$ & $\begin{array}{c}\text { Group B } \\
(\mathrm{n}=22)\end{array}$ & $p$-value* \\
\hline Cosmetic complications & $14(19.2)$ & $6(11.8)$ & $8(36.4)$ & 0.023 \\
$\quad$ Erythema & $13(17.8)$ & $5(9.8)$ & $8(36.4)$ & 0.016 \\
Post-inflammatory hyperpigmentation & $11(15.1)$ & $4(7.8)$ & $7(31.8)$ & 0.014 \\
Atrophy & $8(11.0)$ & $2(3.9)$ & $6(27.3)$ & 0.008 \\
Widening & $5(6.8)$ & $2(3.9)$ & $3(13.6)$ & 0.157 \\
Hypertrophy & $3(4.1)$ & $2(3.9)$ & $1(4.5)$ & $>0.999$ \\
Modified vancouver scar scale score & $2.18 \pm 1.73$ & $1.53 \pm 1.22$ & $3.68 \pm 1.84$ & 0.000 \\
Patient satisfaction score & $3.81 \pm 1.01$ & $4.08 \pm 0.89$ & $3.18 \pm 1.01$ & 0.001 \\
\hline
\end{tabular}

Values are presented as number (\%) or mean \pm standard deviation. Group A: early excision group, group B: delayed excision group. *Analyzed by Mann-Whitney test, chi-square test, Fisher's exact test or independent t-test. 

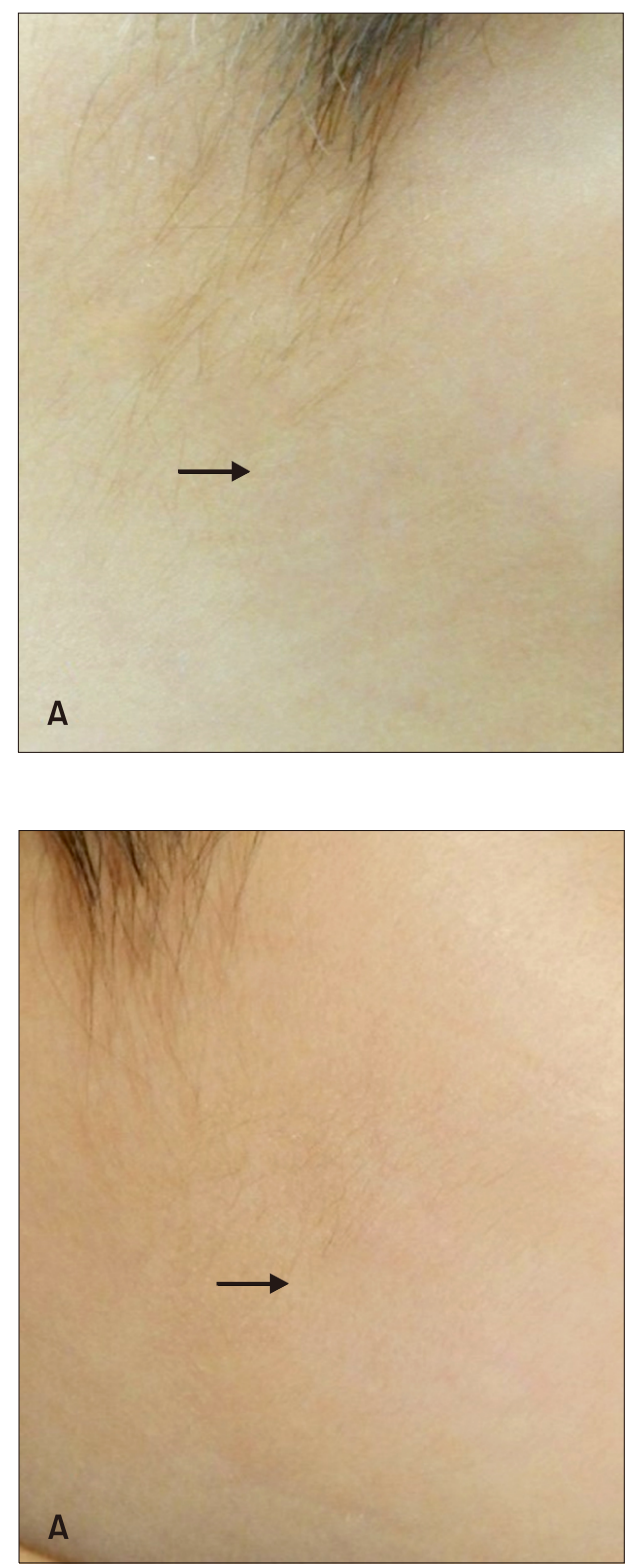

B

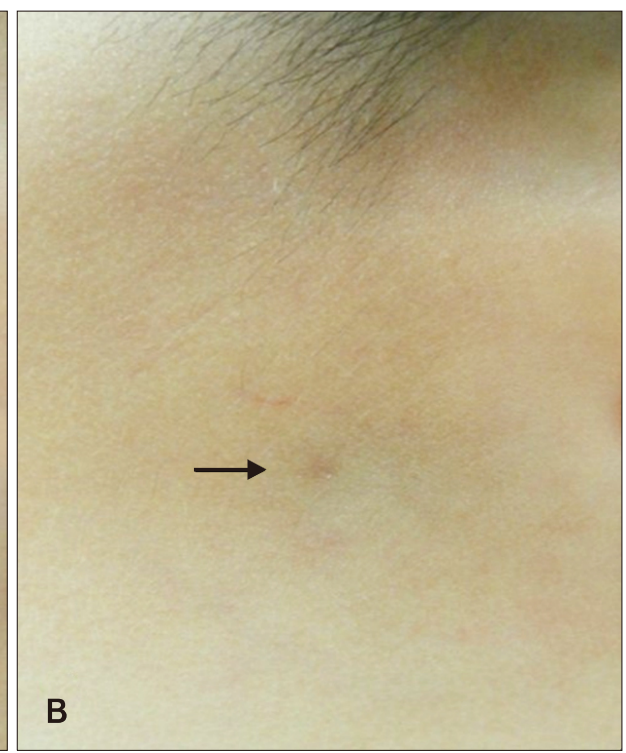

Fig. 4. Representative serial photographs of a patient in group A before surgery $(A)$ and 6 months after surgery (B) on the left cheek. Group A: early excision group.

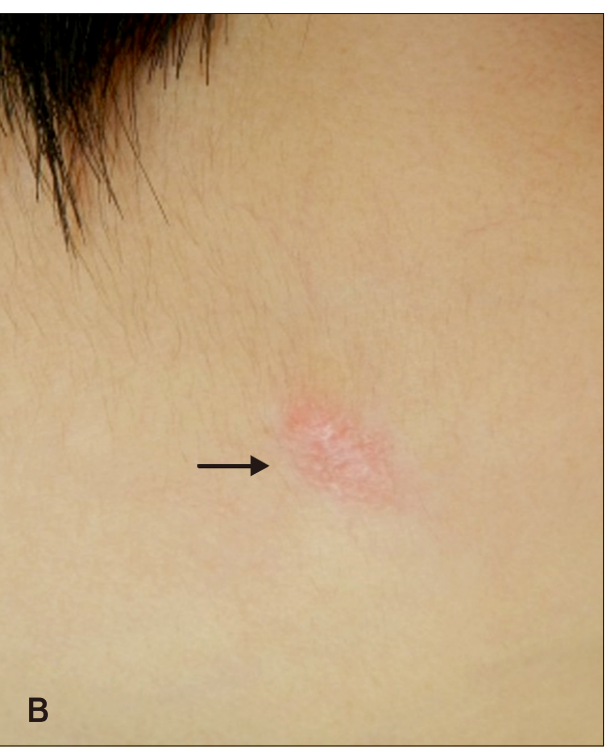

Fig. 5. Representative serial photographs of a patient in group $B$ before surgery $(A)$ and 6 months after surgery (B) on the right cheek. Group B: delayed excision group. tent sign, which was more common in group B $(72.7 \%)$ than in group A (25.5\%). This result also supports that tumor has histopathological evolutionary characteristics toward calcification and ossification over time. Calcification was higher in group B $(95.5 \%)$ than group A $(51.0 \%)$, but inflammatory cell infiltrates, multinucleated giant cells, and hemorrhage were not statistically different between groups. Dystrophic calcinosis cutis is the most common type of cutaneous calcification, which can occur as a result of local degenerated or necrotic tissue, and indicates microscopic cell injury ${ }^{24,25}$. Reiter et al. ${ }^{26}$ reported that pilomatricomas is one of the common causes of dystrophic calcinosis cutis, and approximately $75 \%$ of patients show calcifications. Our findings imply that calcification, rather than inflammatory cell infiltrates itself, may play a role in the difference in cosmetic outcomes between groups. There are obvious distinctions in the evolutionary stages between the two groups. The most common evolutionary stage in group A was stage III (51.0\%), while stage IV was prominent in group B $(77.3 \%)$. Stage IV with calcium deposition creates an anatomical dead space, peripheral tissue damage, and focal necrosis, which also affect poor surgical outcomes.

Complication rates and both scoring systems showed significantly poorer outcomes in group B. Higher complication rates and differences in color, texture, and height matching between the operation sites with the surrounding normal tissue may have resulted in lower cosmetic sat- 
isfaction for both physicians and patients. Interestingly, evolutionary stages have a positive correlation with the mean MVSS $(r=0.670, p<0.05)$. Therefore, surgical excision of pilomatricomas should be recommended as early as possible because of the relations between histopathological evolution of the tumor and possible postoperative cosmetic results.

This study has several limitations. First, this is a retrospective, a single-center study of pediatric patients aged $\leq$ 15 years with a pilomatricoma; thus, the result may not be applicable to all populations. Multicenter prospective studies with a large number of patients are required to validate our results and to explore additional factors associated with surgical outcomes. Second, the disease duration for classifying group A and group B was not further subdivided. Subdivision of disease duration can be helpful for understanding disease entities and evolutionary stages. In conclusion, early surgical excision of pilomatricoma resulted in better cosmetic outcomes than delayed treatment. Therefore, clinicians who care for pediatric patients with pilomatricoma should be aware that early diagnosis and treatment are important to improve overall cosmetic outcomes. We hope that our study will be helpful in determining appropriate operative timing and understanding the characteristics of patients with pilomatricomas.

\section{CONFLICTS OF INTEREST}

The authors have nothing to disclose.

\section{ORCID}

Yong Woo Oh, https://orcid.org/0000-0001-7169-7798

Ho Seok Suh, https://orcid.org/0000-0002-6781-5429

Yu Sung Choi, https://orcid.org/0000-0001-8308-4091

\section{REFERENCES}

1. Julian CG, Bowers PW. A clinical review of 209 pilomatricomas. J Am Acad Dermatol 1998;39(2 Pt 1):191-195.

2. Pirouzmanesh A, Reinisch JF, Gonzalez-Gomez I, Smith EM, Meara JG. Pilomatrixoma: a review of 346 cases. Plast Reconstr Surg 2003;112:1784-1789.

3. Srivastava D, Taylor RS. Appendage tumors and hamartomas of the skin. In: Fitzpatrick TB, Goldsmith LA, editors. Fitzpatrick's dermatology in general medicine. Vol. 1. 8th ed. New York: McGraw-Hill Medical, 2012.

4. Jones CD, Ho W, Robertson BF, Gunn E, Morley S. Pilomatrixoma: a comprehensive review of the literature. Am J Dermatopathol 2018;40:631-641.

5. Kaddu S, Soyer HP, Hödl S, Kerl H. Morphological stages of pilomatricoma. Am J Dermatopathol 1996;18:333-338.
6. Pant I, Joshi SC, Kaur G, Kumar G. Pilomatricoma as a diagnostic pitfall in clinical practice: report of two cases and review of literature. Indian J Dermatol 2010;55:390-392.

7. Yencha MW. Head and neck pilomatricoma in the pediatric age group: a retrospective study and literature review. Int J Pediatr Otorhinolaryngol 2001;57:123-128.

8. Alli N, Güngör E, Artüz F. Perforating pilomatricoma. J Am Acad Dermatol 1996;35:116-118.

9. Honda Y, Oh-i T, Koga M, Tokuda Y. Perforating pilomatricoma: transepithelial elimination or not. J Dermatol 2002; 29:100-103.

10. Fujioka M, Gozo N, Osamu M, Tsuneyuki Y, Takehisa Y. Secondary anetoderma overlying pilomatrixomas. Dermatology 2003;207:316-318.

11. Ohnishi T, Nakamura $Y$, Watanabe S. Perforating pilomatricoma in a process of total elimination. J Am Acad Dermatol 2003;49(2 Suppl Case Reports):S146-S147.

12. Miura T, Yamamoto T. Perforating pilomatricoma with anetodermic epidermis in an adolescent with lymphoma. Pediatr Dermatol 2013;30:e68-e69.

13. Cho S, Whang KK, Hahm JH. Pilomatricoma: a clinical and histopathologic study of 13 cases. Ann Dermatol 2000;12: 179-184.

14. Fearmonti R, Bond J, Erdmann D, Levinson H. A review of scar scales and scar measuring devices. Eplasty 2010;10: e43.

15. Bae SH, Bae YC. Analysis of frequency of use of different scar assessment scales based on the scar condition and treatment method. Arch Plast Surg 2014;41:111-115.

16. Hernández-Núñez $A$, Nájera Botello $L$, Romero Maté $A$, Martínez-Sánchez C, Utrera Busquets M, Calderón Komáromy A, et al. Retrospective study of pilomatricoma: 261 tumors in 239 patients. Actas Dermosifiliogr 2014;105:699705.

17. Kwon D, Grekov K, Krishnan M, Dyleski R. Characteristics of pilomatrixoma in children: a review of 137 patients. Int J Pediatr Otorhinolaryngol 2014;78:1337-1341.

18. Han G, Kim AR, Song HJ, Oh CH, Jeon J. Updated view on epidemiology and clinical aspects of pilomatricoma in adults. Int J Dermatol 2017;56:1032-1036.

19. Kaddu S, Soyer HP, Cerroni L, Salmhofer W, Hödl S. Clinical and histopathologic spectrum of pilomatricomas in adults. Int J Dermatol 1994;33:705-708.

20. Kim JE, Sohn KM, Woo YJ, Jeong KH, Kim M, Lee JD, et al. A clinicoimmunohistopathologic study of anetoderma: is protruding type more advanced in stage than indented type? J Immunol Res 2016;2016:4325463.

21. Venencie PY, Winkelmann RK, Moore BA. Anetoderma. Clinical findings, associations, and long-term follow-up evaluations. Arch Dermatol 1984;120:1032-1039.

22. Graham JL, Merwin CF. The tent sign of pilomatricoma. Cutis 1978;22:577-580.

23. Hwang JY, Lee SW, Lee SM. The common ultrasonographic features of pilomatricoma. J Ultrasound Med 2005;24:13971402.

24. Touart DM, Sau P. Cutaneous deposition diseases. Part II. J Am Acad Dermatol 1998;39(4 Pt 1):527-544; quiz 545-546. 
YW Oh, et al

25. Walsh JS, Fairley JA. Calcifying disorders of the skin. J Am Acad Dermatol 1995;33(5 Pt 1):693-706; quiz 707-710.

26. Reiter N, El-Shabrawi L, Leinweber B, Berghold A, Aberer E.
Calcinosis cutis: part I. Diagnostic pathway. J Am Acad Dermatol 2011;65:1-12; quiz 13-14. 